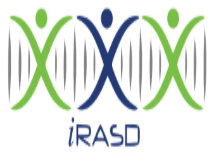

iRASD Journal of Management

Volume 3, Number 3, 2021, Pages 329 - 338

Journal Homepage:

https://journals.internationalrasd.org/index.php/jom

\title{
Environmental Governance and Green Energy: An Administrative Toolkit to Reduce Environmental Degradation
}

\author{
Muhammad Sajjad Hussain ${ }^{1}$, Muhammad Atif Nawaz², Tusawar Iftikhar Ahmad ${ }^{3}$, \\ Muhammad Azhar Bhatti ${ }^{4}$ \\ ${ }^{1}$ Visiting Faculty, Superior University Lahore, Pakistan. Email: sajjadgift@gmail.com \\ 2 Department of Economics, The Islamia University of Bahawalpur, Pakistan, Email: atif.nawaz.baloch@gmail.com \\ ${ }^{3}$ Assistant Professor, Department of Economics, The Islamia University of Bahawalpur, Pakistan. \\ Email: tusawar.iftikhar@iub.edu.pk \\ ${ }^{4}$ Associate Lecturer, Department of Economics, The Islamia University of Bahawalpur, Pakistan. \\ Email: azhar.bhatti219@gmail.com
}

\section{ARTICLE INFO}

\section{Article History:}

Received:

Revised:

Accepted:

November 06, 2021

December 29, 2021

December 29, 2021

Available Online: December 31, 2021

\section{Keywords:}

Environmental governance

Environmental-related taxes

Green energy

Carbon emission

\section{ABSTRACT}

For the last two decades, environmental degradation has become the most serious concern at multiple levels and has gained special attention of literature and policymakers. Strict implementation of the evidence-based policy solutions could serve as a regulatory tool to gradually overcome this issue. The current study examines the role of environmental governance (environmental-related taxes) and green energy (renewable energy consumption and production) on the carbon dioxide (CO2) emission of the ten most $\mathrm{CO} 2$ emitting countries. The study has used economic growth as the control variable. Data has been extracted from the world development indicators (WDI) from 2012 to 2020 . The study employed the robust standard error and fixed effect model (FEM) to examine the linkage among the variables under consideration. The results indicated that environmental governance and green energy have a significant role in reducing environmental degradation in the ten most $\mathrm{CO} 2$ emitting countries in the world. The findings of this empirical and evidence-based study suggest to the relevant environmental management authorities, administrative bodies, and policymakers to incorporate environmental governance and green energy in their environmental management strategies.

(C) 2021 The Authors, Published by iRASD. This is an Open Access article under the Creative Common Attribution Non-Commercial 4.0

\section{Introduction}

The world is witnessing rapid environmental change like global warming etc. from the past few decades. These rapid environmental changes have enhanced the importance of environmental studies. The world is also showing keen interest in the betterment of the environment. A rise in the world's population has also increased human demand for basic necessities that raised the demand for natural resource utilization, hence resulting into environmental degradation. Global warming, disruption of biological equilibrium, and everincreasing environmental pollution are severe modern challenges that endanger human existence. It is critical to limit emission of greenhouse gas in order to avoid the climate changes. There are a number of issues related with the environment, particularly air pollution, is among the most binding shared challenges which hold countries accountable to another in the globalizing world. A number of studies in theoretical as well as empirical perspectives highlighted the importance of the environment ( $\mathrm{Li}$ et al., 2021; Nawaz, Hussain, et al., 2021; Zhuang et al., 2021). In the meantime, our natural environment offers numerous resources to different industries as well as to different nations in order to meet their multiple requirements. The natural environment is taken as the absorber of 
harmful elements like $\mathrm{CO}_{2}$ emission, haze pollution etc. and other sorts of dangerous gases which are generated by different kinds of activities in order to safeguard nature. In this global village, the countries are more focused on their economic growth which accelerates the pressure on the natural environment. Renewable energy (RE) implies toward the energy resources which cover biomass, hydropower, solar, wind etc. It is also predicted that in future the RE is the one of the key source of cleaner as well as sustainable energy (Chien, Kamran, et al., 2021; Mohsin, Kamran, Nawaz, Hussain, \& Dahri, 2021).

The countries around the world are focusing on RE in comparison with nonrenewable and traditional resources. Like, the $25 \%$ production of the European Union nations comes from RE resources. As in the Baltics, the electricity production from wind and hydro is 48 and 32 percent respectively (Balsalobre-Lorente \& Leitão, 2020; Ehsanullah et al., 2021; Nawaz, Seshadri, et al., 2021). For the time being, the demand for RE is increasing with the passage of time in order to achieve economic growth as well as sustainable development targets. In both environment sciences as well as among the policymakers it is assumed that the green or RE will positively impact the environmental governance decoupling from $\mathrm{CO}_{2}$ emission. Though, the studies also proposed that the production of RE does not leads to expected environmental outcomes (Chien, Pantamee, et al., 2021; Ehsanullah et al., 2021).

The role of green energy, RE production, and other etc. to control the degradation of environment is supported by past studies (Charfeddine \& Kahia, 2019; Chien, Sadiq, Kamran, et al., 2021). Environmental issues have the same sever impact for both developed as well as developing countries. Whether it is developed or developing country, they will have to pay special attention towards the stability of its environment in order to safeguard its economy as well as future (Sun et al., 2020; Xiang et al., 2021). The most polluted countries in the world are China, USA, India, South Korea, Russia, Japan, Iran, Saudi Arabia, Germany, \& Indonesia. There is an urgent need of these economies to introduce and implement more regulations regarding environmental degradation in order to safeguard their environment as well as future generations.

Natural resources are the key towards the economic development of any country. The better utilization of natural resources shifts the country status from developing to developed. So, there is urgent need to safeguard the natural resources of the country. The safety of environment will lead to the better utilization of the natural resources that would not only benefit the country's economy in a number of ways but also the society in terms of health etc. There is urgent need to discuss and explore the remedies to mitigate the environmental degradation in these countries that would otherwise lead to human disaster not only in these countries but also in the entire world. The environmental issues, like global warming, air pollution, water pollution etc. have urged the environmentalists to examine the both RE and nonrenewable energy (NRE) factors as well as the other related variable like green energy and environment taxes to control the environmental degradation in the highly polluted economies.

The present study will add in the existing literature in a multiple way. Like, 1) the study is covering one of the important topic relating to the global concerns (i.e., environmental management) although much explored but still not reached at its peak. 2) Chien, Sadiq, Nawaz, et al. (2021), tested environmental degradation in the context of Asian economies, whereas the present study tests the most polluting nations. 3) Aydin and Esen (2018) explored the relationship between $\mathrm{CO}_{2}$ emission and environmental taxes whereas the present study adds the green energy factor. 4) There is no evidence regarding investigating the environmental degradation in developed and developing countries. 5) Inglesi-Lotz and Dogan (2018), investigated the RE consumption with $\mathrm{CO}_{2}$ emission whereas the current study adds another factor i.e. green energy. Regarding its significance, the current study will spotlight the importance of environmental degradation and will help the regulators to develop effective policies regarding environmental degradation. The structure of the present study is comprised of many sections. The first section is about the introduction, and after an introduction, the next section of the current study deals with evidences regarding environmental degradation, environmental governance and green energy in connection with the past studies from the literature. The third section of the study displays the methodology applied for collection of the data on environmental degradation, governance of the environment as well as on green energy in order to analyze the validity 
of the collected data. The fourth and final section of the study presents the comparison of the findings of the current study with that of the similar nature of the studies on the same subject from the literature and thus, approves the results. The last section presents conclusion and future recommendation of the study.

\section{Literature Review}

Global warming has been a source of considerable worry both not in the highly polluted countries but also worldwide, and the major cause of climate change is the release of greenhouse gases i.e., $\mathrm{CO}_{2}$ emission. Climate change will bring a slew of issues that will cost humanity in a sever manners. Since long, the industrial countries development pattern of high energy consumption and pollution has resulted in significant degradation of the environment as well as the ecological destruction (Chien, Sadiq, Nawaz, et al., 2021; Wang \& Zhang, 2022). The increasing energy consumption especially from resources that are non-renewable leads to a high level of pollution. In this context, a number of researchers have expressed interest in dealing with environmental control like environmental degradation. In this context, Shen, Wang, Peng, and Hou (2020) conducted a study on the usage of energy from regular resources i.e. fossil fuels and environmental pollution. The results of the study revealed that extra usage of the energy from regular resources particularly fossil fuel leads to enhance air pollution not only in both developed as well as developing countries. The study was conducted in China by covering the tenure i.e. 20112017 by applying the spatial measurement approach. The findings also proposed that with the passage of time the spatial measurement is weakening with fossil fuel whereas increasing with RE global trends. Similarly, Awodumi and Adewuyi (2020), explored the nexus between consumption of $\mathrm{RE}, \mathrm{CO}_{2}$ emission along with economic growth in Africa. The data covering the tenure from 1980 to 2015 was tested by employing co-integration analysis. The findings proposed positive change in RE and also positive impact on the economic growth. On the other hand in the form of $\mathrm{CO}_{2}$ emission there are mixed trends reported. In addition to this, Sharif, Raza, Ozturk, and Afshan (2019) tested the relationship between $\mathrm{RE}$ and NRE consumption along with $\mathrm{CO}_{2}$ emission. A panel of data from 74 countries covering the tenure from 1990 to 2015 was used. There are different techniques like CIPS unit root test, FMOLS along with heterogeneous panel causality technique etc. The study's findings demonstrated a positive relationship between NRE use and environmental deterioration, but a negative relationship between RE consumption and environmental degradation. Likewise, The link between renewable and $\mathrm{NRE}$ and $\mathrm{CO}_{2}$ emissions was investigated by Inglesi-Lotz and Dogan (2018) with the help of panel estimation approach, which is resilient to cross dependency, was used to assess data from Sub-Saharan Africa spanning the period 1980 to 2011. The study's findings demonstrated that an increase in NRE use leads to a rise in pollution, whereas RE has the opposite effect. Charfeddine and Kahia (2019), tested the relationship between RE consumption and $\mathrm{CO}_{2}$ emission in the MENA region. The data of 24 MENA countries covering the tenure from 1980 to 2015 was tested by employing the panel vector autoregressive (PVAR) model. The results of the study revealed that there is an association between $\mathrm{RE}$ and $\mathrm{CO}_{2}$ emission.

Understanding the link between $\mathrm{CO}_{2}$ emission and economic growth can assist governments in developing more sustainable energy policies as well as energy resource development. Nonetheless, various studies have been conducted to study the link between $\mathrm{CO}_{2}$ emission and economic development (Cai, Sam, \& Chang, 2018; Mikayilov, Galeotti, \& Hasanov, 2018). Likewise, Chen, Wang, and Zhong (2019) tested the relationship between $\mathrm{CO}_{2}$ emission and economic growth from in Chinese perspective. The data from the tenure 1980 to 2014 was tested by employing the technique autoregressive distributed lag (ARDL) bound testing approach. The results of the study proposed that there is a negative association between RE and $\mathrm{CO}_{2}$ emission. Similarly, from a Chinese perspective, the link between $\mathrm{CO}_{2}$ emissions and economic growth was tested by Dong, Sun, Jiang, and Zeng (2018). Environmental Kuznets Curves were used to test the data, which covered the years 1993 to 2016. The findings demonstrated that RE reduces CO emissions in both the long and short term. In the same way, Mikayilov et al. (2018), tested the relationship between economic growth and $\mathrm{CO}_{2}$ emission in Azerbaijan. The environmental Kuznets Curves were tested using time series data of tenure from 1992 to 2013 . The results proved that there is a positive association between $\mathrm{CO}_{2}$ emission and economic growth in Azerbaijan. 
More evaluations of the consequences of various environmental policy measures are being undertaken as the scope of environmental challenges expands. There are number of other factors i.e., environmental taxes etc. formed and intended to address this issue, play an important role in mitigating climate change, which is a key issue in terms of sustainable development. Pollution responsibility is the major market-based economic mechanism actively used in environmental pollution control in this context. Pollution responsibility covers a variety of taxes or levies intended at controlling the behavior of producers and consumers. The goal of such a tax duty is to discourage ecologically harmful behaviors and/or improve incentives for waste reduction. Literature also provides the evidences regarding environmental taxes and $\mathrm{CO}_{2}$ (Baloch et al., 2021; Chien, Hsu, Zhang, Vu, \& Nawaz, 2021). In this context, Aydin and Esen (2018), tested whether the environmental taxes does impact the $\mathrm{CO}_{2}$ emission in European Union. The data was collected from 15 European Union nations by covering the tenure of 1995 to 2013. The results of the study revealed that after attaining a specific level association between environmental taxes and $\mathrm{CO}_{2}$ emission becomes negative. The results also revealed that some specific sector like Transportation has no threshold with $\mathrm{CO}_{2}$ emission. Similarly, Hao, Umar, Khan, and Ali (2021), tested the relationship between green growth, environmental taxes and $\mathrm{CO}_{2}$ emission. The data ranging from 1991 to 2017 was tested by employing the Cross-Sectional Augmented Auto-regressive Distributive lag (CS-ARDL) model. The results of the study revealed that whether it's linear or non-linear terms for green growth but its results in a reduction of $\mathrm{CO}_{2}$ emission. Along with those environmental taxes also results in the depletion of $\mathrm{CO}_{2}$ emission in $\mathrm{G} 7$ countries. In addition to this, Wang and Zhang (2022), tested the impact of environmental regulation (inclusive of environmental taxes) in 282 cities of China. The results revealed that there is a direct impact of environmental regulations on $\mathrm{CO}_{2}$ emission.

\section{Research Methodology}

The article examines the role of environmental-related taxes, RE consumption, and production on the $\mathrm{CO}_{2}$ emission of the ten most $\mathrm{CO}_{2}$ emission generated countries such as China, India, the United States, Japan, Russia, Germany, Saudi Arabia, South Korea, Indonesia, and Iran. The presents study has also used economic growth as the control variable in the study. The current article used the secondary data extracted from the WDI from 2012 to 2020 . The estimation equation is given below:

$C O 2_{i t}=\alpha_{0}+\beta_{1} E R T_{i t}+\beta_{2} R E C_{i t}+\beta_{3} R E P_{i t}+\beta_{4} E G_{i t}+e_{i t}$

Where, $\mathrm{CO}_{2}=$ Carbon Emission, $\mathrm{i}=$ Country, $\mathrm{t}=$ Time Period, $\mathrm{ERT}=$ Environment Related Taxes, REC = Renewable Energy Consumption, REP = Renewable Energy Production, EG = Economic Growth.

The current research has been taken $\mathrm{CO}_{2}$ emission as the dependent variable and measured as the Carbon dioxide damage (\% of GNI). Moreover, the current research has used two independent variables such as environmental governance measured as the environmental-related taxes (\% of GDP) and green energy measured as the "renewable energy production (\% of total energy production)" and "renewable energy consumption (\% of total energy consumption)." Finally, the current literature has used economic growth as the control variable and measured as GDP growth (annual percentage). These measurements and variables are given in Table 1.

\section{Table 1}

Variables with Measurements

\begin{tabular}{lllc}
\hline S\# & Variables & Measurement & Sources \\
\hline 01 & $\mathrm{CO}_{2}$ emission & Carbon dioxide damage (\% of GNI) & WDI \\
02 & Environmental Governance & Environmental related taxes (\% of GDP) & WDI \\
03 & Green Energy & RE production (\% of total energy production) & WDI \\
& & RE consumption (\% of total energy consumption) & WDI \\
04 & Economic Growth & GDP growth (annual percentage) & WDI \\
\hline
\end{tabular}

Firstly, the current research has run the descriptive statistics that provide the variables details such as mean, minimum values, standard deviation, observation used, and maximum values. Secondly, the current article runs the correlation matrix that shows the 
correlation among the understudy variables. Thirdly, the variance inflation factor (VIF) was used to test the multicollinearity assumption. The equations are given below:

$$
\begin{aligned}
& \mathrm{R}^{2} \mathrm{Y} \Longrightarrow Y_{i t}=\alpha_{0}+\beta_{2} X_{2 i t}+\beta_{3} X_{3 i t}+\beta_{4} X_{4 i t}+\beta_{5} X_{5 i t}+e_{i t} \\
& j=R_{Y}^{2}, R_{X 1}^{2}, R_{X 2,}^{2}, R_{X 33}^{2}, R_{X 4,}^{2} R_{X 5}^{2} \\
& \text { Tolrance }=1-R_{j}^{2} \quad \text { VIF }=\frac{1}{\text { Tolerance }}
\end{aligned}
$$

Fourthly, the current research examines the suitable model for analysis using the Hausman test. If the probability value shows less than 0.05 value, then FEM is suitable and vice versa. The equation is given below:

$H=\left(b_{1}-b_{0}\right)\left(\operatorname{Var}\left(b_{0}\right)-\operatorname{Var}\left(b_{1}\right)\right)\left(b_{1}-b_{0}\right)$

In above estimation equation, $b_{0}$ shows "null hypotheses" about the random effect is suitable and $b_{1}$ shows "alternative hypotheses" about FEM are suitable. The FEM is appropriate in this study because the Hausman test probability value is lower than 0.05 . FEM is the best model because it controls the model's heterogeneity issues and provides the best estimations. The equation is given as under:

$Y_{i t}=\beta_{1 i}+\beta_{2} X_{2 i t}+\beta_{3} X_{3 i t}+\beta_{4} X_{4 i t}+\beta_{5} X_{5 i t}+u_{i t}$

In the above estimation equation, subscript (i) represents the "individual country" that marks various countries regarding their features. Using understudy constructs, the FEM equation is shown below:

$C O 2_{i t}=\beta_{1 i}+\beta_{2} E R T_{i t}+\beta_{3} R E P_{i t}+\beta_{4} R E C_{i t}+\beta_{5} E G_{i t}+u_{i t}$

Finally, the "robust standard error" is also used to test the linkage among understudy constructs. This model is also suitable for the study because the data is crosssectional dependent (cross-sections are more than the time series). It also controls the heterogeneity and auto-correlation issues and provides the best estimations. The equation is given below:

$C O 2_{i t}=\beta_{1} E R T_{i t}+\beta_{2} R E P_{i t}+\beta_{3} R E C_{i t}+\beta_{4} E G_{i t}+\varepsilon_{i t}$

\section{4. $\quad$ Research Findings}

Firstly, the current research has run the descriptive statistics that provide the variables details such as mean, minimum values, standard deviation, observation used, and maximum values. The results investigated that the mean value of $\mathrm{CO}_{2}$ was 3.983 percent while the mean value of ERT was 7.093 percent. In addition, the figures also examined that the mean value of REP was 60.764 percent while the mean value of REC was 55.324 percent and the average value of EG was 5.983 percent. Table 2 shows the values of descriptive statistics.

\section{Table 2}

Descriptive Statistics

$\begin{array}{lrrrrr}\text { Variable } & \text { Obs } & \text { Mean } & \text { Std. Dev. } & \text { Min } & \text { Max } \\ \text { CO2 } & 90 & 3.983 & 1.092 & 0.292 & 8.098 \\ \text { ERT } & 90 & 7.093 & 2.055 & 3.021 & 10.843 \\ \text { REP } & 90 & 60.764 & 5.983 & 45.092 & 65.984 \\ \text { REC } & 90 & 55.324 & 4.487 & 43.098 & 63.902 \\ \text { EG } & 90 & 5.983 & 1.922 & 1.272 & 9.094\end{array}$

Secondly, the current article runs the correlation matrix that shows the correlation among the understudy variables. The statistics have been shown that ERT, REP, and Rec have a negative association with $\mathrm{CO}_{2}$ while EG has a positive association with $\mathrm{CO}_{2}$. Table 3 shows results regarding the correlation. 
Table 3

Matrix of Correlations

\begin{tabular}{lrrrrr}
\hline Variables & CO2 & ERT & REP & REC & EG \\
\hline CO2 & 1.000 & & & & \\
ERT & -0.183 & 1.000 & & & \\
REP & -0.543 & 0.765 & 1.000 & \\
REC & -0.453 & -0.543 & -0.663 & 1.000 & \\
EG & 0.321 & 0.233 & 0.422 & -0.432 & 1.000 \\
\hline
\end{tabular}

Thirdly, VIF was used to test the multicollinearity assumption. The statistics exposed no issue of multicollinearity because the VIF values are less than five. Table 4 mentioned below shows the test of VIF.

Table 4

Variance Inflation Factor

\begin{tabular}{lrr}
\hline & VIF & $\mathbf{1 / V I F}$ \\
\hline ERT & 3.982 & 0.251 \\
REP & 2.911 & 0.334 \\
REC & 2.265 & 0.442 \\
EG & 2.883 & 0.347 \\
Mean VIF & 3.010 &. \\
\hline
\end{tabular}

Fourthly, the current research examines the suitable model for analysis using the Hausman test. If the probability value shows less than 0.05 value, then FEM is suitable and vice versa. The figures exposed that FEM is suitable because the probability value is lower than 0.05 . Table 5 shows these findings.

Table 5

Hausman Test

\begin{tabular}{ll}
\hline & Coef. \\
\hline Chi-square test value & 5.883 \\
P-value & 0.001 \\
\hline
\end{tabular}

The results related to the FEM indicated that environmental-related, taxes RE consumption and production have a negative association with environmental degradation. The figures also highlighted that EG has a positive association with $\mathrm{CO}_{2}$. Table 6 shows FEM figures.

Table 6

Fixed Effect Model

\begin{tabular}{|c|c|c|c|c|c|c|c|}
\hline $\mathrm{CO2}$ & Beta & S.D. & t-value & p-value & L.L. & U.L. & Sig \\
\hline ERT & -3.983 & 1.609 & -2.48 & 0.010 & -4.923 & -1.542 & ** \\
\hline REP & -2.998 & 0.992 & -3.02 & 0.002 & -3.282 & -1.653 & $* * *$ \\
\hline REC & -3.912 & 1.252 & -3.12 & 0.000 & -5.333 & -2.090 & $* * *$ \\
\hline EG & 4.983 & 2.092 & 2.38 & 0.014 & 1.139 & 2.998 & $* *$ \\
\hline Constant & 6.093 & 2.902 & 2.10 & 0.022 & 1.992 & 2.927 & ** \\
\hline R-squared & & 0.465 & Number of & & & & 90 \\
\hline F-test & & 3.992 & Prob $>\mathrm{F}$ & & & & 0.064 \\
\hline
\end{tabular}

Table 7

Robust Standard Error

\begin{tabular}{llllllc} 
CO2 & Beta & S.D. & t & P>t & L.L. & U.L. \\
\hline ERT & -1.992 & 0.872 & -2.284 & 0.012 & -1.882 & -0.923 \\
REP & -2.009 & 0.723 & -2.779 & 0.009 & -2.773 & -0.934 \\
REC & -3.992 & 1.092 & -3.656 & 0.000 & -1.099 & -0.923 \\
EG & 2.112 & 0.660 & 3.200 & 0.002 & 1.222 & 2.911 \\
CCons & 9.092 & 4.099 & 2.218 & 0.022 & 3.982 & 8.202 \\
\hline
\end{tabular}

The results related to the "robust standard error" indicated that environmentalrelated taxes, RE consumption, and production have a negative association with environmental degradation. The figures also highlighted that EG has a positive association 
with $\mathrm{CO}_{2}$. Table 7 shows these associations.

\subsection{Discussions}

The study results have shown environmental-related taxes in a negative association with the $\mathrm{CO}_{2}$ emissions driving environmental degradation. The results are supported by the recent study of Guo et al. (2018), which examines the impact of environmental-related regulations through taxes on environmental degradation. This study highlights that the government put large taxes or charges on the individuals or enterprises who are engaged in such activities as cause the emission of greenhouse gases like $\mathrm{CO}_{2}$ emissions. This is an effective way to control the environmental degradation within the country. These results agree with the previous study of Shahzad (2020) by suggesting that tax imposing on the part of the government on activities damaging the environmental elements like air, water, soil, and the natural resources and living beings grow there, encourage ecological friendly activities and reduce environmental degradation. The results also revealed the negative association between $\mathrm{RE}$ consumption and $\mathrm{CO}_{2}$ emissions and environmental degradation. These results are in line with the past study of Bilgili, Koçak, and Bulut (2016), which shows that the utilization of RE resources does not leave any negative impact on the climate as these do not emit harmful gases like $\mathrm{CO}_{2}$. The reduction of $\mathrm{CO}_{2}$ by utilizing RE in place of non-renewable source of energy help enterprises to keep the environment safe from deterioration.

The study results also stated the negative link between $\mathrm{RE}$ production and $\mathrm{CO}_{2}$ emissions, a factor of environmental degradation. The study of Chen et al. (2019), supports these results. This study highlights that in the countries where there is a trend to produce RE for utilizing in performing economic activities like production processes, marketing, and logistics, there are minimum greenhouse gas emissions like $\mathrm{CO}_{2}$ in the air, and the environmental degradation can be controlled. These results are also in line with the previous work of Razmjoo et al. (2021), according to which the production of RE includes plantation and forestry, which consume $\mathrm{CO}_{2}$ found in the air and use of heat. Thus, the production of RE minimizes greenhouse gases and reduces the chances of environmental degradation. The study results have shown economic growth in a positive association with the $\mathrm{CO}_{2}$ emissions driving environmental degradation. These results match with the article of Mikayilov et al. (2018), which reveal that when the country is showing fast development in the international market, the use of machinery, plants, and other economic processes which require energy is at large scale. The increased use of energy causes an increase in the emission of greenhouse gases including $\mathrm{CO}_{2}$ and in this situation, the natural environment is also damaged. These results are also in line with the past study of Cai et al. (2018), which posits that the high economic growth denotes increase in the production processes and the increased energy consumption for the increased productivity cause emission of greenhouse gases like $\mathrm{CO}_{2}$ and environmental destruction in the form of damage to the natural resources and other living creatures.

\subsection{Implications}

The study focuses on the role of environmental governance (through environmentrelated taxes), RE consumption, and RE production, and economic growth on environmental degradation. A large number of pollutants can cause environmental deterioration, and mostly the studies have dealt with greenhouse gases collectively as the determiner of environmental degradation. The present study differentiates with the selection of $\mathrm{CO}_{2}$ emission out of all pollutants for determining environmental degradation. In the previous studies, environmental governance has been discussed in relation to environmental degradation, and this examines environmental governance along with the economic growth on environmental degradation. The current study provides guidelines to the relevant authorities and policymakers in formulating and implementing policies aimed at providing solution to environmental degradation. The study has a broad significance for all countries, especially the countries having large industries and economic activities, as, such countries have more potential threat to be exposed to environmental degradation. The study provides measures that the governing environmental authority and economic enterprises must take into consideration in order to reduce environmental degradation. The study highlights that $\mathrm{CO}_{2}$ emissions cause environmental degradation, but the $\mathrm{CO}_{2}$ emissions can be overcome 
with environmental governance practices like environment-related taxes, RE consumption, and RE production with economic growth.

\section{Conclusions and Limitations}

The study was aimed at investigating the degree to which environmental governance through environment-related taxes, $\mathrm{RE}$ consumption, and $\mathrm{RE}$ production reduce $\mathrm{CO}_{2}$ emission and environmental degradation and also to analyze the economic growth effects on $\mathrm{CO}_{2}$ emission. Data were collected, from the most polluted countries across the world, on the variables: environmental governance, RE consumption, and RE production and economic growth, and $\mathrm{CO}_{2}$ emissions. The findings showed a reduction in $\mathrm{CO}_{2}$ emissions due to environmental governance, RE consumption, and RE production. The results showed that an increase in the rate of taxes imposed on the activities or resources which can deteriorate the environmental quality is helpful in reducing $\mathrm{CO}_{2}$ emission. The results indicated that the consumption and production of RE resources in order to provide energy for both economic and domestic practices minimize the $\mathrm{CO}_{2}$ emissions and is an administrative tool against environmental degradation. But the increase in economic growth leads the country towards environmental degradation by enhancing $\mathrm{CO}_{2}$ emissions.

The present study also carries many limitations, which are expected to be removed in the next literature on environmental degradation. This study examines the role of environmental governance only in reducing environmental degradation. Having left all other possible factors, which also determine the countries' capacity to overcome environmental degradation, have made the study less comprehensive. Thus, the forthcoming studies must incorporate a greater number of factors to see their role in environmental degradation. Moreover, this study takes only one of the pollutants, $\mathrm{CO}_{2}$, as the sole indicator of environmental degradation. In the future studies, it is expected that all the other indicators of environmental degradation must also be given equal attention to conduct comprehensive research.

\section{References}

Awodumi, O. B., \& Adewuyi, A. O. (2020). The role of non-renewable energy consumption in economic growth and carbon emission: Evidence from oil producing economies in Africa. Energy Strategy Reviews, 27, 100-117. doi:https://doi.org/10.1016/j.esr.2019.100434

Aydin, C., \& Esen, Ö. (2018). Reducing CO2 emissions in the EU member states: Do environmental taxes work? Journal of Environmental Planning and Management, 61(13), 2396-2420. doi:10.1080/09640568.2017.1395731

Baloch, Z. A., Tan, Q., Kamran, H. W., Nawaz, M. A., Albashar, G., Hameed, J. J. E., Development, \& Sustainability. (2021). A multi-perspective assessment approach of renewable energy production: policy perspective analysis. Environment, Development and Sustainability, 1-29. doi:https://doi.org/10.1007/s10668-02101524-8

Balsalobre-Lorente, D., \& Leitão, N. C. (2020). The role of tourism, trade, renewable energy use and carbon dioxide emissions on economic growth: evidence of tourism-led growth hypothesis in EU-28. Environmental Science and Pollution Research, 27(36), 45883-45896. doi: 10.1007/s11356-020-10375-1

Bilgili, F., Koçak, E., \& Bulut, Ü. (2016). The dynamic impact of renewable energy consumption on $\mathrm{CO} 2$ emissions: a revisited Environmental Kuznets Curve approach. Renewable and Sustainable Energy Reviews, 54, 838-845. doi:https://doi.org/10.1016/j.rser.2015.10.080

Cai, Y., Sam, C. Y., \& Chang, T. (2018). Nexus between clean energy consumption, economic growth and CO2 emissions. Journal of cleaner production, 182, 10011011. doi:https://doi.org/10.1016/j.jclepro.2018.02.035

Charfeddine, L., \& Kahia, M. (2019). Impact of renewable energy consumption and financial development on $\mathrm{CO} 2$ emissions and economic growth in the MENA region: A panel vector autoregressive (PVAR) analysis. Renewable Energy, 139, 198-213. doi:https://doi.org/10.1016/j.renene.2019.01.010

Chen, Y., Wang, Z., \& Zhong, Z. (2019). CO2 emissions, economic growth, renewable and non-renewable energy production and foreign trade in China. Renewable Energy, 131, 208-216. doi:https://doi.org/10.1016/j.renene.2018.07.047 
Chien, F., Hsu, C.-C., Zhang, Y., Vu, H. M., \& Nawaz, M. A. (2021). Unlocking the role of energy poverty and its impacts on financial growth of household: is there any economic concern. Environmental Science and Pollution Research, 1-14. doi: https://doi.org/10.1007/s11356-021-16649-6

Chien, F., Kamran, H. W., Nawaz, M. A., Thach, N. N., Long, P. D., \& Baloch, Z. A. (2021). Assessing the prioritization of barriers toward green innovation: small and medium enterprises Nexus. Environment, Development and Sustainability, 1-31. doi:https://doi.org/10.1007/s10668-021-01513-x

Chien, F., Pantamee, A. A., Hussain, M. S., Chupradit, S., Nawaz, M. A., \& Mohsin, M. (2021). Nexus between financial innovation and bankruptcy: evidence from information, communication and technology (ict) sector. The Singapore Economic Review, 1-22.

Chien, F., Sadiq, M., Kamran, H. W., Nawaz, M. A., Hussain, M. S., \& Raza, M. (2021). Comovement of energy prices and stock market return: environmental wavelet nexus of COVID-19 pandemic from the USA, Europe, and China. Environmental Science and Pollution Research, 1-15. doi:https://doi.org/10.1007/s11356-021-12938-2

Chien, F., Sadiq, M., Nawaz, M. A., Hussain, M. S., Tran, T. D., \& Le Thanh, T. (2021). A step toward reducing air pollution in top Asian economies: The role of green energy, eco-innovation, and environmental taxes. Journal of Environmental Management, 297. doi:https://doi.org/10.1016/j.jenvman.2021.113420

Dong, K., Sun, R., Jiang, H., \& Zeng, X. (2018). CO2 emissions, economic growth, and the environmental Kuznets curve in China: What roles can nuclear energy and renewable energy play? Journal of Cleaner Production, 196, 51-63. doi:https://doi.org/10.1016/j.jclepro.2018.05.271

Ehsanullah, S., Tran, Q. H., Sadiq, M., Bashir, S., Mohsin, M., \& Iram, R. (2021). How energy insecurity leads to energy poverty? Do environmental consideration and climate change concerns matters. Environmental Science and Pollution Research, 28(39), 55041-55052. doi:10.1007/s11356-021-14415-2

Guo, X., Ho, M. S., You, L., Cao, J., Fang, Y., Tu, T., \& Hong, Y. (2018). Industrial water pollution discharge taxes in China: a multi-sector dynamic analysis. Water, 10(12), 1742-1762. doi:https://doi.org/10.3390/w10121742

Hao, L.-N., Umar, M., Khan, Z., \& Ali, W. (2021). Green growth and low carbon emission in G7 countries: How critical the network of environmental taxes, renewable energy and human capital is? Science of The Total Environment, 752, 14-29. doi:https://doi.org/10.1016/j.scitotenv.2020.141853

Inglesi-Lotz, R., \& Dogan, E. (2018). The role of renewable versus non-renewable energy to the level of $\mathrm{CO} 2$ emissions a panel analysis of sub- Saharan Africa's Big 10 electricity generators. Renewable Energy, 123, 36-43. doi:https://doi.org/10.1016/j.renene.2018.02.041

Li, W., Chien, F., Hsu, C.-C., Zhang, Y., Nawaz, M. A., Iqbal, S., \& Mohsin, M. (2021). Nexus between energy poverty and energy efficiency: Estimating the long-run dynamics. Resources Policy, 72. doi:https://doi.org/10.1016/j.resourpol.2021.102063

Mikayilov, J. I., Galeotti, M., \& Hasanov, F. J. (2018). The impact of economic growth on CO2 emissions in Azerbaijan. Journal of Cleaner Production, 197, 1558-1572. doi:https://doi.org/10.1016/j.jclepro.2018.06.269

Mohsin, M., Kamran, H. W., Nawaz, M. A., Hussain, M. S., \& Dahri, A. S. (2021). Assessing the impact of transition from nonrenewable to renewable energy consumption on economic growth-environmental nexus from developing Asian economies. Journal of Environmental Management, 284. doi:https://doi.org/10.1016/j.jenvman.2021.111999

Nawaz, M. A., Hussain, M. S., Kamran, H. W., Ehsanullah, S., Maheen, R., \& Shair, F. (2021). Trilemma association of energy consumption, carbon emission, and economic growth of BRICS and OECD regions: quantile regression estimation. Environmental Science and Pollution Research, 28(13), 16014-16028.

Nawaz, M. A., Seshadri, U., Kumar, P., Aqdas, R., Patwary, A. K., \& Riaz, M. (2021). Nexus between green finance and climate change mitigation in N-11 and BRICS countries: empirical estimation through difference in differences (DID) approach. Environmental Science and Pollution Research, 28(6), 6504-6519. doi:https://doi.org/10.1007/s11356-020-10920-y 
Razmjoo, A., Kaigutha, L. G., Rad, M. V., Marzband, M., Davarpanah, A., \& Denai, M. (2021). A Technical analysis investigating energy sustainability utilizing reliable renewable energy sources to reduce $\mathrm{CO} 2$ emissions in a high potential area. Renewable Energy, 164, 46-57. doi:https://doi.org/10.1016/j.renene.2020.09.042

Shahzad, U. (2020). Environmental taxes, energy consumption, and environmental quality: Theoretical survey with policy implications. Environmental Science and Pollution Research, 27(20), 24848-24862. doi:https://doi.org/10.1007/s11356-020-08349-4

Sharif, A., Raza, S. A., Ozturk, I., \& Afshan, S. (2019). The dynamic relationship of renewable and nonrenewable energy consumption with carbon emission: A global study with the application of heterogeneous panel estimations. Renewable Energy, 133, 685-691. doi:https://doi.org/10.1016/j.renene.2018.10.052

Shen, N., Wang, Y., Peng, H., \& Hou, Z. (2020). Renewable Energy Green Innovation, Fossil Energy Consumption, and Air Pollution-Spatial Empirical Analysis Based on China. Sustainability, 12(16), 1-18. doi:10.3390/su12166397

Sun, H., Awan, R. U., Nawaz, M. A., Mohsin, M., Rasheed, A. K., \& Iqbal, N. (2020). Assessing the socio-economic viability of solar commercialization and electrification in south Asian countries. Environment, Development and Sustainability, 1-23. doi:https://doi.org/10.1007/s10668-020-01038-9

Wang, H., \& Zhang, R. (2022). Effects of environmental regulation on CO2 emissions: An empirical analysis of 282 cities in China. Sustainable Production and Consumption, 29, 259-272. doi: https://doi.org/10.1016/j.spc.2021.10.016

Xiang, H., Ch, P., Nawaz, M. A., Chupradit, S., Fatima, A., \& Sadiq, M. (2021). Integration and economic viability of fueling the future with green hydrogen: An integration of its determinants from renewable economics. International Journal of Hydrogen Energy, 46(77), 38145-38162. doi:https://doi.org/10.1016/j.ijhydene.2021.09.067

Zhuang, Y., Yang, S., Chupradit, S., Nawaz, M. A., Xiong, R., \& Koksal, C. (2021). A nexus between macroeconomic dynamics and trade openness: moderating role of institutional quality. Business Process Management Journal, 27(6), 1703-1719. doi:https://doi.org/10.1108/BPMJ-12-2020-0594 